\title{
Changing the Potential Distribution of Turkey Oak (Quercus cerris L.) under Climate Change in Turkey
}

\author{
Ahmet Mert ${ }^{1 *}$, Kürşad Özkan², \\ Özdemir Şentürk ${ }^{3}$, Mehmet Güvenç Negiz ${ }^{4}$ \\ ${ }^{1}$ Süleyman Demirel University, Isparta, Turkey \\ ${ }^{2}$ Department of Soil and Forest Ecology, Faculty of Forestry, \\ Süleyman Demirel Univ., 32260, Isparta, Turkey \\ ${ }^{3}$ Mehmet Akif Ersoy University, Gölhisar Vocational School, Burdur, Turkey \\ ${ }^{4}$ Süleyman Demirel University, Sütçüler Prof. Dr. Hasan Gürbüz \\ Vocational School, Isparta, Turkey
}

Received: 6 February 2016

Accepted: 16 March 2016

\begin{abstract}
Turkey oak ( $Q$. cerris) is an important species for rehabilitating soils, promoting conservation, and increasing biodiversity. It is also a fire-resistant plant. To predict the potential distribution of this species under climate change is crucial for better understanding the future of ecosystems - in particular Mediterranean ecosystems. The purpose of this study was to generate the potential distribution maps of Turkey oak under current and changing climate in the Sütçüler district located in the translation zone of the Mediterranean region. Classification and regression tree technique (CART) was applied to model the distribution of the species (response data) using current climatic data, parent material, landform types, and topographical position index (explanatory data). Geographic information system (GIS) was used for visualizing current potential distribution of the species. Next, the obtained distribution model was simulated to the digital data of climatic change scenario b2 of IPCC. In this way, changing the potential distribution of Turkey oak along the district was predicted under climate change.
\end{abstract}

Keywords: global warming, habitat suitability, oaks, predictive distribution models

\section{Introduction}

The fact that oaks profoundly affect ecosystem balance due to their varied functional properties has been known for a long time. Oaks are essential from the standpoint of nutrient cycling (flow of the energy), light availability,

*e-mail: ahmetmert81@hotmail.com soil conservation and rehabilitation, resilience, and forest ecosystem health. Also, they contribute functional, structural, and species diversities and site productivity of ecosystems. The oaks have abilities to perform those functions due mostly to fast decomposition rates of their leaf litter and high variation in the shapes and sizes of their crowns. In addition, oaks play an important role in filling ecosystem gaps. 
Oaks are guarantor species from succession stages until the climax term in the forests.

Over the past decade, the issue of climate change has risen rapidly to an important position on international scientific and political agendas due to the fact that there is strong evidence of a pending and profound change in global climate as a result of human activities [1-2]. Recent estimates predict an increase in global mean temperature of 2.4 to $6.4^{\circ} \mathrm{C}$ by the end of this century [2]. To better understand the potential impacts of the current warming trend, considerable effort has gone into predicting the effect of future climate scenarios on various flora and fauna [3-19].

The Mediterranean region is a vulnerable place in terms of climate change, and the Mediterranean basin is expected to be more strongly affected by ongoing global climate change than most regions of the world [20]. That is why oaks have become much more important elements of ecosystems, in particular Mediterranean ecosystems due to their functional properties to mitigate the effects of projected climate change.

In this study, Turkey oak (Quercus cerris L.) was selected as our focal species. We decided to study this species because it is one of the most common native oaks throughout the Mediterranean region of Turkey. We attempted a study to model potential distribution of Turkey oak using classification and regression tree technique (CART) under current and future climatic conditions in the Sütçüler District located in the Mediterranean region.

\section{Material and Methods}

\section{Site Description}

The study area of the Sütçüler District lies between $37^{\circ} 29^{\prime} 17^{\prime} \mathrm{N}$ latitude and $30^{\circ} 59^{\prime} 46^{\prime \prime} \mathrm{E}$ longitude, 250-2,500 $\mathrm{m}$ a.s.1. according to the UTM coordinate system (Fig. 1). It is bordered to the north by Egirdir Lake, Kovada Lake, and Koca Mountain (1,742 m); to the northeast by Beyşehir Lake, Kuyucak (2,337 m) and Dedegöl $(2,980 \mathrm{~m})$ mountains, and Tota Plateau; in the west by Sarp Mountain $(2,548 \mathrm{~m})$; in the south by Ak Mountain and Sanlı Plateau; to the southwest by Karacaören Lake; and to the west and northwest by Kara Mountain and Burdur Lake (Fig. 1).

A typical Mediterranean climate characterized by dry-hot summers and rainy winters prevails in the district [21]. Mean annual precipitation in the region is $950.1 \mathrm{~mm}$ annually, with the most arid and hottest months being July and August with a mean annual temperature of $13.1^{\circ} \mathrm{C}$ and $54 \%$ average relative humidity. Above 1,400 m a.s.l. a mountainous Mediterranean climate with a higher precipitation prevails [22]. Minimum relative humidity is recorded during August (43\%) and maximum during December (66\%). Heavy rains occur in November, December, January, and February, while the dry period extends from the beginning of June until the end of October [21, 23].

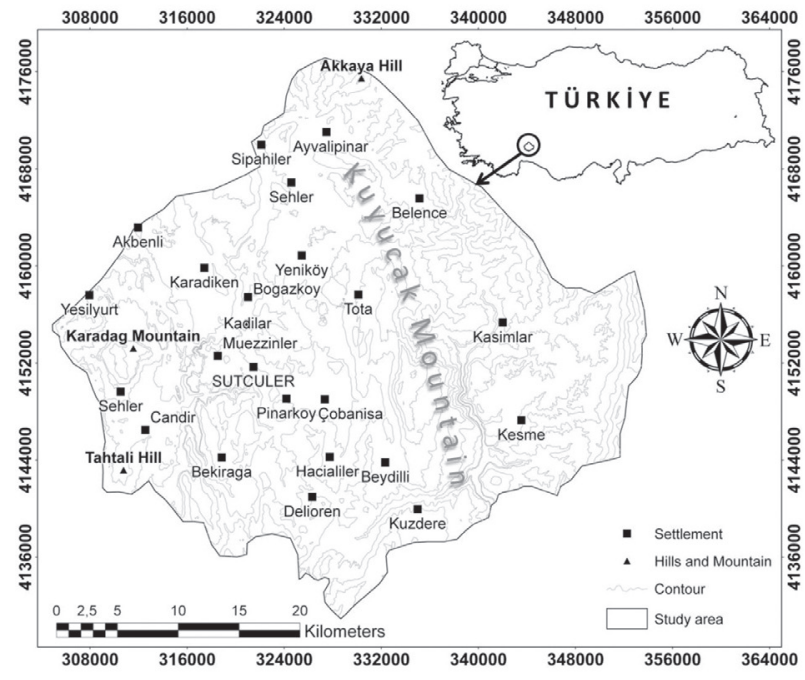

Fig. 1. Location map of the study area (Sütçüler District) in southern Turkey.

Flora of the study area is composed of 63 families, 225 genus, and 478 species. More than $55 \%$ of plant species belong to the Fabaceae, Asteraceae, Carypohyllaceae, Lamiacea, Brassicaceae, Boraginaceae, Rosaceae, Apiaceae, Scrophulariaceae, and Ranunculaceae families [24]. About 50\% of the study area is covered by Mediterranean mountain forests composed mainly of Pinus brutia Ten. (Brutian pine), Pinus nigra Arn. ssp. pallasiana (Lamb.) Holmboe (Crimean pine), Ouercus spp., Juniperus spp., and some relic stands of Cedrus libani (Lebanon cedar) [23].

\section{Data and Statistical Evaluation}

The data were collected from 1,040 sample plots, at which the presence and absence of Turkey oak was recorded. Binary (absence/presence) data of Turkey oak was taken as a response variable in order to obtain its spatial distribution model. Climatic and topographical variables were taken as explanatory variables. A 30-arcsecond $\left(0.00083^{\circ}\right.$ by $\left.0.00083^{\circ}\right)$ resolution of bioclimatic layers (representing annual trends, seasonality, and extreme or limiting environmental factors) were used for 1950-2000 from the WorldClim data set (downloaded 05 March 2011) [25].

All bioclimatic layers, including annual mean temperature (BIO1), mean diurnal range (BIO2), isothermality (BIO3), temperature seasonality (BIO4), max temperature of warmest month (BIO5), min temperature of coldest month (BIO6), temperature annual range (BIO7), mean temperature of wettest quarter (BIO8), mean temperature of driest quarter (BIO9), mean temperature of warmest quarter(BIO10), mean temperature of coldest quarter (BIO11), annual precipitation (BIO12), precipitation of wettest month (BIO13), precipitation of driest month (BIO14), precipitation seasonality (BIO15), precipitation of wettest quarter (BIO16), precipitation of driest quarter (BIO17), precipitation of warmest quarter 
(BIO18), and precipitation of coldest quarter (BIO19) were resampled with cubic convolution (the most commonly implemented higher-order resampling technique) to a pixel resolution of $100 \mathrm{~m}$ by $100 \mathrm{~m}$ grids.

Elevation and bedrock geology maps were provided from OGM (General Directory of Forestry) and MTA (General Directorate of Mineral Research and Exploration). Slope (SLOP) was derived from the elevation-built function provided by ArcGIS. Topographic position index (TPI) and landform category maps were derived from elevation maps by adding a "tpi_jen.avx" file to the Arcview extensions directory [26]. These maps were resampled at a resolution of $100 \mathrm{~m}$ by $100 \mathrm{~m}$ grids by using nearest neighbor interpolation as the simplest technique for assigning pixel values to the new grid.

The resampled bedrock map was composed of eight types: conglomerate (ROCK1), marly (ROCK2), radiolarite (ROCK3), basalt, spilite (ROCK4), ophiolic melange (ROCK5), dolomite (ROCK6), limestone (ROCK7), and sandstone (ROCK8). Landform types were composed of 10 classes: canyons, deeply incised streams (LFC1), midslope drainages, shallow valleys (LFC2), upland drainages, headwaters (LFC3), U-shape valleys (LFC4), plains (LFC5), open slopes (LFC6), upper slopes, mesas (LFC7), local ridges/hills in valley (LFC8), midslope ridges, small hills in plains (LFC9) and $\mathrm{mt}$ tops, and high ridges (LFC10).

A classification and regression tree technique (CART) was applied to describe potential distribution of Turkey oak in the study.

CART analysis is a nonparametric tree-building technique. Its essential purpose is to partition the main data into homogeneous subgroups. In this way, the data is represented by a tree structure in which internet nodes denote best split predictor variables. The branches of the nodes denote the criteria values of the split variables. Leaves denote the final response classes. The paths from the root node (top node) to leaf (terminal node) show the decision rules that maximize the distinction among the classes and minimize the diversity in each class.

By using CART, both categorical and numeric response data can be modeled. If a response variable is categorical, then "classification trees"; if it is continuous, "regression trees" are used [27-30]. In this context, since our response variable is categorical data, we used the classification tree technique. The CART method uses the Gini impurity measure to decide the purity for the binary dependent variable.

For a node $t$, the Gini index of impurity, $g(t)$, is defined in the following way:

$$
g(t)=\sum_{j \neq i} p(j \mid t) p(i \mid t)
$$

... where $i$ and $j$ are categories of the target variable. Since our response variable is binary data (occurrence or nonoccurrence of Lebanon cedar), the equation for the index is reduced to:

$$
g(t)=2 p(1 \mid t) p(2 \mid t)
$$

The index equals 0 since all recodes in the node belong to only one category, which means the node is purity. To select the best predictor variable of a node, every possible variable is scored and one with the best score which represents the greatest reduction in impurity is selected. For any node $t$, suppose that there is a candidate split $s$ of the node, which divides it into the left division $t_{L}$ and the right division $t_{R}$ :

$$
\phi(s, t)=g(t)-p_{L} g\left(t_{L}\right)-p_{R} g\left(t_{R}\right)
$$

...where $P_{R}$ is the proportion of cases of child node $t$ sent to the right, and $P_{L}$ to child node on the left. It can define a candidate set $S$ of binary $s$ at each node. When it starts at the root note $\mathrm{t}_{1}$, it looks for the division $s^{*}$, among all possible $S$, with a greater reduction value of impurity:

$$
\phi\left(s^{*}, t_{1}\right)=\max \underset{s \in S}{\phi}\left(s, t_{1}\right)
$$

The dataset is divided into two subgroups by a perfect split ${ }_{S}$, which causes $g\left(t_{L}\right)=g\left(t_{R}\right)=0$. The recursive partitioning algorithm loops until it is impossible to continue (i.e., when only one case remains or when all the cases belong to the same class).

A maximum tree is produced when it grows until all terminal nodes are perfect purity. The maximal tree is generally over-adjusted because of the random or noisy cases in the learning dataset. The CART uses an "overgrowing and prune back" procedure to get an optimal tree that is fitted to signal rather than noise. In this study we used all the data for training purposes by using 10-fold cross-validation, i.e., the data was divided into 10 subgroups, and 10 separate models fit. The first model used subgroups 2-10 for training, and subgroup 1 for testing. The second model used groups 3-10 and 1 for training, and group 2 for testing, and so on. In all cases, an independent test subgroup was available. Misclassification error rates were then calculated for each subset. This process was performed for each size of tree, and the tree with the smallest misclassification error rate based on the independent test set was then chosen as the optimal tree [27-28, 31-32]. DTREG software was used to build classification trees [33].

After performing CART, if-then rules were written for each path of tree graphs in an excel file to calculate the predicted values of the response variable. The following formulas were used for continuous explanatory variables (Formula 5) and categorical explanatory variables (Formula 6 ) to find predicted values $\left(B_{n}\right)$ being the leaf value of $n$. terminal node:

$$
\begin{aligned}
& =\operatorname{IF}\left(A N D\left(X_{L 1 i j} \# N d_{1} ; X_{L 2 i j} \ldots \ldots X_{L n i j} \# N d_{n}\right)\right. \\
& =I F\left(A N D \left(O R\left(X_{L C l i j}=c_{1} ; X_{L C l i j}=c_{2} ; \ldots X_{L C l i j}=c_{n}\right)(6)\right.\right.
\end{aligned}
$$


$\ldots$ where $X_{L 1 i j} \ldots \ldots X_{L n i j}$ denotes divisor explanatory variables for the $i$-th column and the $j$-th row from the first level (L1) (top node) to the last level ( $L n$ ) (terminal node) of a given path, $N d$ represents the criteria value of a divisor explanatory variable at each level of the relevant branch, $X_{L C I i j}$ denotes the categorical deviser variables, and $c_{n}$ denotes categories provided from if-then rules in a given categorical variable.

Finally, the predicted values were calculated at each grid $(100 \times 100 \mathrm{~m})$ (totally for 127,875 grids). All grids were digitized in order to generate the potential distribution map of response variable.

The current potential distribution model of Turkey oak was then simulated to the digital maps of an emission scenario representing liberal (b2) estimation, which was acquired from www.worldclim.org/futdown.htm for the year 2080. This model (HadCM3) was prepared by Hadley Centre for Climate Prediction and Research. Consequently, the distribution model of Turkey oak obtained from CART was visualized under current and future climatic conditions.

\section{Results and Discussion}

As mentioned before, a response data was obtained from the 1,040 sampling points. We have detected the presence of Turkey oak from 292 sampling points. Due to high correlations among climatic variables, we first applied principle component analysis (PCA) to the climatic data matrix in order to reduce the number of the climatic variables.

According to the result of the applied PCA, the first two components include eigenvalues more than 1 and percentages of variance more than $10 \%$. Those components explained $97 \%$ of total variance. The variables having the highest values for the first and second components were BIO6 (0.991) and BIO12 (0.996), respectively. That is why instead of all climatic variables, we preferred to use the two representative climatic variables to obtain a distribution model. In another words, LFC, ROCK, TPI, SLOP, BIO6, and BIO12 were considered to obtain the current potential distribution model of Turkey oak.

According to the results of the applied CART running 10 -fold cross validation, the minimum validation relative error occurred with 21 nodes. Accuracy, sensitivity, specificity and F-measure of the training set were found to be $83.75 \%, 59.93 \%, 93.05 \%$, and 0.67 , while those values for the test set were $80.87 \%, 54.11 \%, 91.31 \%$, and 0.61 , respectively. The area under ROC curve (AUC) of the model was calculated and found to be 0.837 for the training set and 0.817 for the test set. The tree model was built in six variables. From the highest to the lowest contribution percentage, the tree model was built by BIO6 (100\%), BIO12 (50\%), SLOP (27\%), ROCK7 (23\%), TPI (7\%), and ROCK8 (6\%).

Twenty-one rules were formulated as " $I F(A N D$ (BIO6 $<=-37.5) ; 0.0962 ; 0)$ (rule 1$) ; \operatorname{IF}(A N D(B I O 6>-37.5$; ROCK7 = 0; SLOP>14.5; BIO6>17.5); 0;0) (rule 21)" in Excel files to calculate the predicted values of each of the grids and to visualize the tree model along the district (Fig 2a). Next, the model was simulated using digital climatic data of b2 scenario (Fig. 2b). Finally, intersection areas of the potential distribution maps under current and changing climate (Fig. 2c) were formed to detect the most suitable grids by considering a threshold value of 0.60 .

In response to the needs of environmental managers, predictive distribution models have been increasingly used to generate potential distribution maps of the species in recent years. Such models have been used for wildlife [34], bird species [35-37], insect species [38-39], and plant species [40] in terrestrial ecosystems, and fish [41], jellyfish [42], and mammal species [43] in aquatic or marine ecosystems. Besides, they have been used to assess the potential impacts of climate change on species distributions [44-45].

Predictive distribution models are mainly divided into two groups, namely mechanistic (static) models and correlative (dynamic) models. To apply the mechanistic models, detailed ecophysiological information of the target species should be provided. Unfortunately, it is not easy to provide such information for all species. On the contrary, such information is not required for applying correlative models. That is why correlative models have

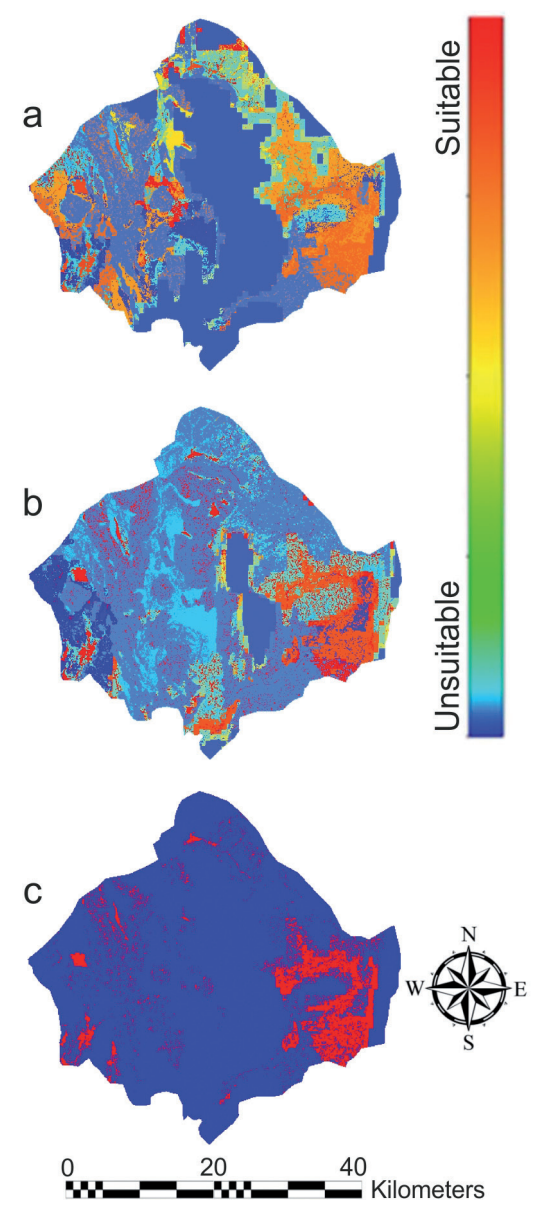

Fig. 2. Current a) and future potential distribution b) maps of Turkey oak and intersection areas c) of a and b maps in the Sütçüler District of Turkey. 
been much more frequently used for predicting species' distribution. According to the type of response variable, correlative models are described as group discrimination techniques and profile techniques. The presence and absence data (binary data) of a given species is required for application of group discrimination techniques while only presence data is evaluated using profile techniques.

CART, one of the most frequently used techniques among group discrimination techniques, is a hierarchical, rule-based, non-parametric method. That is why we preferred to use CART to model potential distribution of Turkey oak. In this study, the results obtain from the applied CART show that the tree model was chiefly built by $\mathrm{BIO} 6$ and $\mathrm{BIO} 12$. In other words, climatic variables play dominant roles for the distribution of the oak in Sütçüler.

According to the distribution model - especially for the southerneastern part of the study area including Kesme village - some parts of the areas located west and south of Karadağ and in the immediate environs of Karadiken village, Kadılar village, and Sütçüler seem to be the most suitable sites for the oak, while unsuitable sites coincide with the upper part of Kuyucak Mountain.

\section{Conclusion}

The simulated model shows that the majority of the areas located in the western and southern parts of Kocadag will no longer be suitable for its occurrence due to global warming at the end of this century, while there will not be a significant variation in the southeastern part of the study area. To confirm this appearance by considering a threshold value with 0.6 , intersection areas of current and future potential distribution maps were generated. The obtained intersection map showed that the southeastern part of the study area will seem to remain suitable until the end of this century.

Turkey oak is able to be preferred or used as a target species for achievement in restoration or afforestation efforts in the intersection areas between its current and future distribution maps. Obtained information from the map illustrating intersection areas of the species is particularly important to prepare accurate long-term management and conservation plans and minimize the negative effects of climate change intended for not only Turkish oak but also the Sütçüler ecosystems.

In the Mediterranean region, there are several oaks species such as $Q$. coccifera, $Q$. ithaburensis, $Q$. trojana, $Q$. pubescens, $Q$. infectoria, and $Q$. vulcanica, as well as Q. cerris. Within the context of the subject of this study, preparation of an integrated broad-scale research project should be designed and prepared, including all oak species due to their multi-functional properties to develop longterm conservation and management plans, to mitigate the negative effects originating from climate change, and to enable sustainable use of goods and services in the Mediterranean ecosystems of Turkey.

\section{Acknowledgements}

We especially thank Dr. Serkan Gülsoy and Dr. Halil Süel for their kind support during our field studies.

\section{References}

1. KARL T.R., TRENBERTH K.E. Modern global climate change. Science. 302, 17193, 2003.

2. INTERGOVERNMENTAL PANEL ON CLIMATE CHANGE (IPCC) [Online]. Climate Change: The Physical Science Basis. Summary for Policy Makers, [Accessed 20.04.2013.]. 2007, Available: http://www.ipcc.ch/, 2007.

3. GALLEGO-SALA A., CLARK J., HOUSE J., ORR H., PRENTICE I.C., SMITH P., CHAPMAN S. Bioclimatic envelope model of climate change impacts on blanket peatland distribution in Great Britain. Climate Research, 45, 151, 2010.

4. PACHECO S., MALIZIA L.R., CAYUELA L., Effects of climate change on subtropical forests of South America. Tropical Conservation Science. 3 (4), 423, 2010.

5. EVANGELISTA P.H., KUMAR S., STOHLGREN T.J., YOUNG N.E. Assessing forest vulnerability and the potential distribution of pine beetles under current and future climate scenarios in the Interior West of the US. Forest Ecology and Management, 262 (3), 307, 2011.

6. LATTA G., TEMESGEN H., ADAMS D., BARRETT T. Analysis of potential impacts of climate change on forests of the United States Pacific Northwest. Forest Ecology and Management, 259 (4), 720, 2010.

7. SOMMER J.H., KREFT H., KIER G., JETZ W., MUTKE J., BARTHLOTT W. Projected impacts of climate change on regional capacities for global plant species richness. Proceedings of the Royal Society of London B: Biological Sciences, rspb20100120, 2010.

8. ENGLER R., RANDIN C.F., VITTOZ P., CZÁKA T., BENISTON M., ZIMMERMANN N.E., GUISAN A. Predicting future distributions of mountain plants under climate change: does dispersal capacity matter? Ecography, 32 (1), 34, 2009.

9. RANDIN C.F., ENGLER R., NORMAND S., ZAPPA M., ZIMMERMANN N.E., PEARMAN P.B., GUISAN A. Climate change and plant distribution. Local models predict high-elevation persistence. Global Change Biology. 15, $1557,2009$.

10. VAN ZONNEVELD M., KOSKELA J., VINCETI B., JARVIS A. Impact of climate change on the distribution of tropical pines in Southeast Asia. Unasylva. 231/232 (60), 24, 2009.

11. POMPE S., HANSPACH J., BADECK F., KLOTZ S., THUILLER W., KÜHN I. Climate and land use change impacts on plant distribution in Germany. Biol. Lett. 4, 564-, 2008.

12. TRIVEDI M.R., BERRY P.M., MORECROFT M.D., DAWSON T.P. Spatial scale affects bioclimate model projections of climate change impacts on mountain plants. Global Change Biology. 14, 1089, 2008.

13. HAMANN A., WANG T., Potantial effects of climate change on ecosystem and tree species distribution in British Columbia. Ecology. 87 (11), 2773, 2006.

14. SHI J.B., LI D.Q., XIAO W.F. A review of impacts of climate change on birds: Implications of long-term studies. Zoological Research. 27, 637, 2006. 
15. CHAMBERS L.E., HUGHES L.,WESTON M.A. Climate change and its impact on Australia's avifauna. Emu. 105, 1, 2005.

16. WALTHER G.R., POST E., CONVEY P., MENZEL A., PARMESAN C., BEEBEE T.J., BAIRLEIN F. Ecological responses to recent climate change. Nature. 416, 389, 2002.

17. KRITICOS D.J., SUTHERST R. W., BROWN J.R., ADKINS S.W., MAYWALD G.F. Climate change and potential distribution of an invasive alien plant: Acacia nilotica ssp. indica in Australia. Journal of Applied Ecology. 40, 111, 2003.

18. PAULI H., GOTTFRIED M., GRABHERR G., Effects of Climate Change on the Alpine and Nival Vegetation of the Alps. J. Mt. Ecol. 7, 9, 2003.

19. SHAFER S.L., BARTLEIN P.J., THOMPSON R.S., Potantial Changes in the Distribution of Western North America Tree and Shrup Taxa under Future Climata Scenarios. Ecosystems. 4, 200, 2001.

20. PETIT R.J., HAMPE A., CHEDDADI R. Climate changes and tree phylogeography in the Mediterranean. Taxon. 54 (4), 877, 2005

21. GOVERNMENT METEOROLOGICAL INSTITUTE (DMI) Meteorological Data of Sutculer District between 1975-1993. Sutculer/Isparta, Turkey, 2006.

22. FONTAINE M., AERTS R., ÖZKAN K., MERT A., GULSOY S., SUEL H., MUYS B. Elevation and exposition rather than soil types determine communities and site suitability in Mediterranean mountain forests of southern Anatolia, Turkey. Forest Ecol Manag. 247, 18, 2007.

23. OZKAN K., GULSOY S., Effects of environmental factors on the productivity of crimian pine (Pinus nigra ssp. pallasiana) in Sutculer, Turkey. J. Environ. Biol. 30 (6), 965, 2009.

24. OZCELIK H., KORKMAZ M., Contributions to the flora of Sutculer- Isparta (Turkey). Bull. Pure Appl. Sci. 21, 1, 2002.

25. HIJMANS R.J., CAMERON S.E., PARRA J.L., JONES P.G., JARVIS A. Very high resolution interpolated climate surfaces for global land areas. Int J Climatol. 25, 1965, 2005.

26. WEISS A. Topographic Position and Landforms Analysis. In: ESRI User Conference, San Diego, CA, 2001.

27. BREIMAN L., FRIEDMAN J., STONE C.J., OLSHEN R.A. Classification and Regression Trees. In: Wadsworth International Group, CRC Press, Belmont, California, USA, 1984

28. MCKENNEY D.W., PEDLAR J.H. Spatial models of site index based on climate and soil properties for two boreal tree species in Ontario, Canada. Forest Ecol Manag. 175, 497, 2003.

29. CHU C.M., TSAI B.W., CHANG K.T. Integrating Decision Tree and Spatial Cluster Analysis for Landslide Susceptibility Zonation. World Academy of Science, Engineering and Technology. 59, 470, 2009.

30. NAVARRATE E., ESPINOSA M. Using the Non-Parametric Classifies CART to Model Wood Density. J Data Sci. 9, 261, 2011.
31. DE'ATH G., FABRICIUS K.E. Classification and Regression Trees: A Powerful Yet Simple Technique for Ecological Data Analysis. Ecology. 81 (11), 3178, 2000.

32. MOISEN G.G. Classification and Regression Tree. In: Encyclopedia of Ecology, In: Jorgensen SE (ed), 582, 2008.

33. MATHSOFT, S-PLUS 4 Guide to Statistics. In: MathSoft, Inc., Seattle, WA, 1997.

34. JOHNSON C.J., GILLINGHAM M.,P. An evaluation of mapped species distribution models used for conversation planning. Environmental Conservation. 32 (2), 1, 2005.

35. MARTINEZ J.A., SERRANO D., ZUBEROGOITIA I. Predictive models of habitat preferences for the Eurasian eagle owl Bubo bubo: a multiscale approach. Ecography, 26, $21,2003$.

36. PETERSON A.T., PAPES M., EATON M. Transferability and model evaluation in ecological niche modeling: a comparison of GARP and Maxent. Ecography. 30, 550, 2007.

37. ORTEGA-HUERTA M.A., PETERSON A.T. Modeling ecological niches and predicting geographic distributions: a test of six presence - only methods. Revista Mexicana de Biodiversidad. 79, 205, 2008.

38. GANESHAIAH K.N., BARVE N., NATH N., CHANDRASHEKARA K., SWAMY M., UMA SHAANKER R. Predicting the potential geographical distribution of the sugarcane woolly aphid using GARP and Diva-Gis. Current Science. 85, 1526, 2003.

39. GALLEGO D., CÁNOVAS F., ESTEVE M.A., GALIÁN J. Descriptive biogeography of Tomicus (Coleoptera: Scolytidae) species in Spain. Journal of Biogeography. 31, 2011, 2004

40. VETAAS O.R., GRYTNES J.A. Distribution of vascular plant species richness and endemic richness along the Himalayan elevation gradient in Nepal. Global Ecology \& Biogeography. 11, $291,2002$.

41. SOUSA P., AZEVEDO M., GOMES M.C. Species-richness patterns in space, depth, and time (1989-1999) of the Portuguese fauna sampled by bottom trawl. Aquatic Living Resources. 19, 93, 2006.

42. DRAKE J.M., BOSSENBROEK J.M. The potential distribution of Zebra Mussels in the United States. BioScience. 54 (10), 931, 2004.

43. KASCHNER K., WATSON R., TRITES A.W. Mapping world-wide distributions of marine mammal species using a relative environmental suitability (RES) model. Marine Ecolocy Progress Series. 316, 285, 2006.

44. GUISAN A., THEURILLAT J. Assessing alpine plant vulnerability to climate change: a modeling perspective, Integrated Assessment. 1, 307, 2000.

45. THOMAS C.D., CAMERONA., GREEN R.E., BAKKENES M., BEAUMONT L.J., COLLINGHAM Y. C., HUGHES L. Extinction risk from climate change, Nature. 427, 145, 2004. 